\title{
LOGO TASARIMINDA RENK
}

\author{
Gültekin AKENGIN', Asuman AYPEK ARSLAN²,
}

\section{A. Çisem YAYÇILI ÖZEN ${ }^{3}$}

\section{ÖZ}

Logo tasarımı yaparken önem verilmesi gereken ilkelerden biri de renk algısıdır. Tercih edilecek olan rengin tüketiciyi etkilemek için doğru ve etkili kullanılması gerekmekte, öncelikle, renk-ürün ilişkisi, rengin psikolojideki yeri, kategorilere göre renkler incelenmeli, logo tasarımı sırasında bu bilgilerden yararlanılmalıdır. Rengin tasarıma etkileri, kolay tanınmayı sağlaması, zıtlıklar oluşturup dikkat çekmesi, çağrışımlar yapabilmesi ve bilinçdışı tepkilere yol açmasıdır. Bu sebeple tasarımcı renk seçimine oldukça önem verir. Tasarımını oluştururken logonun kullanılacağı yer, hedef kitle ve ürün özellikleri renk seçimini etkileyen faktörlerdir.

Anahtar Kelimeler: Renk, Logo, Grafik Tasarımı

Akengin, Gültekin. Aypek Arslan, A. veYayçılı Özen, A. Çisem "Logo Tasarımında Renk". idil 6.31 (2017): 1077-1088.

Akengin, G. Aypek Arslan, A. Yayçılı Özen, A.Ç. Logo Tasarımında Renk. (2017). Logo Tasarımında Renk. idil, 6 (31), s.1077-1088.

\footnotetext{
${ }^{1}$ Doçent Dr., Gazi Üniversitesi Sanat ve Tasarım Fakültesi Görsel Sanatlar Bölümü, gultekinakengin(at)gazi.edu.tr

${ }^{2}$ Araş. Gör. Dr., Gazi Üniversitesi Sanat ve Tasarım Fakültesi Görsel Sanatlar Bölümü, aypek(at)gazi.edu.tr

${ }^{3}$ Gazi Üniversitesi, Güzel Sanatlar Enstitüsü, Grafik Tasarım Ana Sanat Dalı, Yüksek Lisans Öğrencisi,

cisemyaycili(at)gmail.com
} 


\title{
LOGO DESIGN COLOR
}

\begin{abstract}
One of the ways to be considered when designing a logo is color perception. The preferred color to be consumed must be used correctly and effectively to affect the consumer. Firstly, the color-product relationship, the place in the color psychology, the colors should be examined according to the categories, and this information should be used during logo design. The design effects of colors make it easier to recognize, to create contrasts, to attract attention, to make associations, and to lead to unconscious reactions. For this reason, the designer places great importance on color selection. The place where the logo is used while creating the design, the target audience and the product characteristics are the factors that influence the color selection.
\end{abstract}

Keywords:. Color, Logo, Graphic Design 


\section{GíRIŞ}

Renk, 1şı̆̆ın değişik dalga boylarının gözün retina tabakasına ulaşmasıyla ortaya çıkan bir algılamadır. İnsan beyni öncelikle renk ve görsel ilişkileri algılar daha sonra diğer ayrıntıları çözümler. Görmenin gerçekleştiği her an renklerin, duygularımız ve bilinçaltımızda farklı etkileri olur. Bu etkiler davranış şeklimizi ve algılama biçimimizi etkiler (Özer, 2014). Geçmişten günümüze renk kullanımına bakacak olursak, renkler; dini ayinlerde, gizlenme ya da korkutma amaciyla, güzelleşmek adına, kültürel eğlencelerde, kimliğini ve ait olduğu milletini belirlemede, bir duyguyu ifade etmede ve daha birçok eylemde kullanılmıştır. İnsanlık tarihimizin başlangıcından bu yana renkler hayatımızda etkili olmuş ve algı üzerinde önemli bir rol oynamıştır. Renklerin hayatımızın her alanında bu kadar büyük önem taşıması, insan psikolojisi açısından renklerin çeşitlendirilmesi ve değerlendirilmesine olanak sağlanmıştır.

Renk, farklılașan dalga uzunluklarının ve frekanslarının, 1șık dalgalarının gözler üzerindeki etkisidir. Bu 1şık dalgaları, beyaz 1şı̆̆ 1 yaratır. Renk olgusu 1şıkta var olur. Ancak ışığın kendisi, insan gözüne renksiz görünür. Renge sahip olan tüm objeler, sadece rengin yansıtıcıları ya da ileticileridir. Işık dalgaları, gökkuşağındaki renk düzeni gibi farklı renklerden meydana gelir. Bunlar, mor, indigo (mavi- mor), mavi, yeşil, sarı, turuncu, kırmızıdır (Öztuna, 2007). "Renklerin nasıl algılandı̆̆ konusunda bazı açıklanamayan boşluklar olmasına rağmen renk, mesaj- iletişim döngüsü içerisinde görsel algıya doğrudan etki eden bir tasarım elemanı olarak nitelendirilebilir" (Arıkan, 2008).

Logonun tanımını yapacak olursak; kurumları temsil eden, onların özelliklerini yansıtan anlam yüklü ve özel tasarlanmış semboller ya da biçimlerdir (Akıncı, 1998). Logo, kurumun ya da markanın bir dışavurum şeklidir. Bu nedenle logonun oluşumu, markaların kendilerini doğru ifade edebilmesi için önem taşır.

\section{Renk İncelemesi}

Renk, sanatçılar için olağanüstü zenginlikte bir araçtır. Renk kavramının farklı bilim alanlarında değişik şekillerde tanımlandığı görülmektedir. Rengi psikolojik olarak tarif edenler, onun bizde zaten var olan bir duygu olduğunu, maddi olmaktan ziyade sübjektif bir değer olarak var olduğunu savunurlar. Rengi fiziksel bir durum olarak açıklayanlar ise rengin tayfla, ölçülerle, rakamlarla belirlenebilen fiziksel bir durum olduğunu ifade ederek rengin her türlü titreşimdeki 1şık dalgalarından ibaret olduğunu, gözün 1 şı titreşimlerini sinirler vasıtasıyla beyne ileterek rengin idrak edilmesini sağladığını belirtmektedirler (Atalayer, 1994). 
Genelde renk kavramı, 1şık rengi (hue) ve boya rengi (color) olarak iki ayrı biçimde kullanılmaktadır. Bu karmaşık yapısından dolayı, renk hakkında sanatçılar ve bilim adamları farklı teoriler üretmektedirler. Hurvvitz ve Day (1995), Feldman'ın bu konudaki görüşlerini şöyle aktarmaktadırlar: "Bazı renk sistemleri estetikten çok, alg1 fizyolojisi ya da algı psikolojisi ile ilgilidir. Diğerleri ise boyaların, boya maddelerinin (pigmentlerin) ve renkli maddelerin tanımlanması ve sınıflandırılmasının endüstriyel zorunluluklarından ortaya çıkmış olabilir. Sanatçılar, bu sınıflandırmanın herhangi birinde bilimsel bir temelden çok tamamen sezgisel bir yaklaşımla boya renkleriyle çalışırlar." (Hurwitz ve Day, 1995).

Renk, çok güçlü bir tasarım elemanıdır ve tasarım üzerindeki herhangi bir elemanın vurgulanmasında oldukça etkindir. Kâğıt yüzey üzerine, siyah bir pastel boya ile işaret konulduğunda ortaya çıkan şeyin çizgi mi, yoksa biçim mi olduğu karıştırılabilir. Ancak boya uygulanmış ise orada renk vardır.

Renk fonksiyonları, bilişsel ve duygusal etki düzeylerinde olmak üzere iki durumda kabul edilebilir. Bilişsel düzeyde renk, yaprakların sonbaharda renklerinin değişmesinde olduğu gibi kuramsal tanımlayıcı terimler ile bayraklar ve trafik işaretlerinde kullanıldığı gibi sembolik terimlerin bilgisini taşımaktadır. Duygusal etki düzeyinde renk, psikolojik yakınlıklar uyandırmakta ve bu suretle duygusal bir ruh hali yaratmaktadır. Bir tasarımcı, rengin psikolojik ve duygusal açıdan insanları etkilediği gerçeğiyle tasarımlarında rengi bilinçle kullanmak durumundadır.

Bilim insanları rengi, retina üzerinden sinir sistemimize etki eden fiziki bir güç olarak kabul ederlerken, ressamlar için renk konusu bu kadar da karmaşık değildir. Ressamlar için renk, diğer elemanlarla yakın ilişkisi olan, yaşamsal bir ögedir. Ressamlar ile bilim insanlarının renk terminolojileri zaman zaman farklılıklar göstermektedir. Renk tonu (hue); renk tayfinda bulunan renklerdir. Ancak bilimsel açıdan renk, obje üzerinden yansıyan ışı̆̆ın dalga boyu ile ilgili, sınırlandırılmış bir kavramdir.

Ana renkler mavi, kırmızı, sarı, ara renkler turuncu, yeşil ve mordur. Renk çemberinde ana renklerin karşısında yer alan renkler ise "komplementer renkler"dir. Komplementer renkler karıştırıldığında birbirlerini nötralize ederek grileşirler. Renk çemberinde birbirlerine bitişik olarak görülen renkler ise uygun renkler (harmonius colours) olarak adlandırılırlar. Sarı ile yeşil, mor ile mavi örneğinde olduğu gibi he4r grup kendi içinde ortak bir renge sahiptir (Gökaydın, 1998). 
Renk konusunda sık karşılaşılan bir başka kavram da sıcak-soğuk renklerdir. Sıcak renkler; sarı, turuncu, kırmızı; soğuk renkler ise, mavi, yeşil ve mordur. Mittler (1994), soğuk renklerin; su ve gökyüzünün soğukluğuyla yakınlığı olduğunu, bu renklerin yoğun bir şekilde mavi ve yeşil içerdiklerini ve ayrıca renk çemberinde sıcak renklerin karşılarında bulunduklarını belirtir. Yazara göre sıcak renkler de ateş ve güneşin sıcaklığıyla ilintilidir. Bu renkler de yoğun bir şekilde kırmızı ve sarı içerirler, renk çemberindeki yerleri ise soğuk renklerin karşılarıdır. Bir yüzey üzerindeki soğuk renkler daha geride görünürlerken, sıcak renkler etkileriyle daha önde görünürler (Mitler, 1994).

Günlük hayatımızda sıcça kullandığımız renkler, gördüğümüz zaman bizi heyecanlandıran renkler, nötr olduğumuz renkler ya da gördüğümüz zaman bizi rahatsız eden, tercih etmediğimiz renkler vardır. Fakat bir çoğumuzun renklerin bize hissettirdiklerinden ve etkilerinden haberdar değiliz, renkler kimi zaman mutlu kimi zaman da hüzünlü olmamıza neden olur. Örneğin canlı renkler bize enerji verirken, soğuk renkler mutsuz olmamıza neden olur. Renk görsel bir olgu olmasına rağmen bilincimiz yolu ile vücuda gelir yani göz vasıtasıyla duyulan renk algılarına dönüşür. $\mathrm{Bu}$ aşamadan sonra rengin psikolojik etkileri ortaya çıkar. Her rengin bir psikolojik etkisi vardır. Yapılan psikolojik araştırmalara göre renklerin insanların üzerinde korku, sıkıntı, acı, neşe ve sakinlik verici özellikleri gözlemlenmiştir.

\section{Tasarımcı Açısından Rengin Önemi}

Tasarımcı için renk ifade aracıdır. Vermek istediği mesajı, ortaya çıkartmak istediği duyguları ve bilinçaltında oluşan hisleri göz önüne alarak, kullandığı renklerle tasarımın çözümlemesini yapar. $\mathrm{Bu}$ nedenle tasarımcı için renk, oluşturacağı tasarımdaki en önemli etkenlerindendir. Türkiye'de rengin oluşturduğu sembol başka ülkelerin kültürel yapısına göre farklılık gösterebilir. Bir ülkede pozitif anlamı olan bir rengin başka bir ülkede negatif bir anlamı olabilir. Bu sebeple bir tasarımyapılırken, hangi ülkede uygulandığına bakmakta yarar vardır. Bir ürünün tasarım sürecinde görsel unsurlar tasarımcı tarafindan belirlenirken, renk seçiminde hedef kitleye bakılmalı, hedef kitlenin beklentileri doğrultusunda bir renk seçimi yapılmalı ve tasarımı en iyi şekilde ifade etmelidir. Örneğin; ana okulu ve kreşlerde kullanılan logolarda olabildiğince canlı ve enerji verici renkler kullanılırken, bir banka logosunda daha olgun ve sakin renkler kullanılır. 

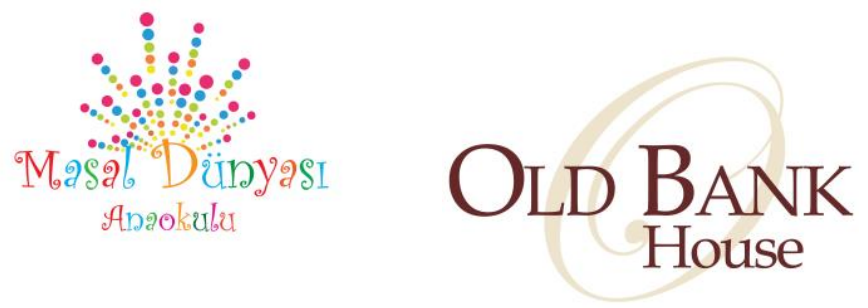

\section{Renklerin Logo Üzerinde Kullanımı}

Tasarım sürecinde yapılan logonun faaliyet alanı, hedefi ve hedef kitlesi dikkate alınarak renk tercihinde bulunulur. Bir marka için tasarlanacak logonun tüketiciye doğru mesajı vermesi, ilgisini çekmesi ve tüketiciyle duygusal bir bağ oluşturması esas alınır. Hazırlanacak olan logonun kullanım alanları da logonun oluşumunda büyük rol oynar. Çünkü logo sadece ürünün üzerinde değil, web sitesinde, kurumsal kimliğinde, üniformalarda, her türlü reklam tabelalarında ve ofis içerisinde de etkileyici görünmelidir. Logo için seçilen renk mutlaka beyaz üzerinde denenmelidir. Oluşturulan yazı, şekil ve renk kombinasyonu bu şekilde test edilebilir (Wheeler, 2003).

Tasarımcıların bir diğer büyük önem vermeleri gereken konu ise seçilen rengin baskıda nasıl göründüğüdür. Çoğu zaman bilgisayar ortamında hazırlanan logoların renk seçimleri, baskı sırasında farklı tonlara dönebilmektedir. Baskı sisteminde yaygın olarak CMYK(Cyan, Magenta, Yellow, Key-Black) renk karışımı kullanılır. Renk kullanımı sırasında, renklerin kültürlere göre anlam değişikliği oluşturduğunu bilmemiz gerekir. Bu nedenle renk seçimi yapılırken hedef kitleyi kültürel bakımdan da incelememiz gerekmektedir. Batı kültüründe saflığın göstergesi olan beyaz, Hint kültüründe yas tutmak anlamındadır. Renklerle düşüncelerin kültürel eşleştirilmeleri bilinçaltında yattıklarından kökleşmiştir (Holtzschue, 2009).

Ünlü renk psikoloğu Jill Morton başarılı bir renk dizaynı için dört altın kuralı şöyle sıralıyor; "İki veya üç renk kullanın: Bilimsel araştırmalar, beyinin dört ve dörtten fazla renk bombardımanına maruz kaldığında, dikkatini başka tarafa yönelttiğini ortaya koyuyor. Aynı aileden renkleri bir arada kullanın: Sarı, sarı-yeşil ve sarı-turuncu renklerin hepsi sarı ailesine dahildir. Renk çarkında birbirlerine yakın yerlerdedirler. Bu renkler birbirlerine bağlıdırlar ve tasarım için güzel bir akıcılık 
sağlar. Zıtlıkları deneyin: Örneğin turuncu-mavi, yeşil-pembe, sarı-mor birbirlerinin zıttıdır ve güçlü kontrasta dayanan güzel bir renk harmonisi yaratabilirler. Okunurluk için doğru kontrastı yakalayın: yazı rengiyle zemin renginin uyumu, yazının okunmasını kolaylaştırır. Yetersiz kontrast okuyucunun gözlerini yorar. Örneğin siyah zemin üzerine mavi yazı pek doğru bir kombinasyon olmayacaktır” (Türk, 2014).

\section{RENKLERE GÖRE LOGO İNCELEMELERİ}

\section{Kırmızı Renkli Logolar}

Ana renkler arasında yer alan kırmızı; sıcak, canlı, enerji verici bir renktir. Aynı zamanda iştah açar, kan basıncını artırır. Aşk ve tutkuyu temsil eder. Kırmızının iştah açıcı özelliğinden dolayı genellikle gıda sektörü kırmızı rengini tercih etmektedir. "En dinamik ve en kuvvetli renk kırmızıdır. Bu renk canlılık, girişkenlik, dışa dönüklük, irade, güç, cinsel güç, kızgınlık, hırs ve olumluluk anlamına gelir. Kırmızı sevenler çoğunlukla neşeli ve hareketlidirler. Kırmızı, sevgi ve nefret duygusunu birlikte içerir. $\mathrm{Bu}$ renk insan üzerinde canlandırıcı, heyecan verici ve kışkırtıcı bir etki bırakır. Enerji ve heyecan verdiği için kırmızı; ülke bayraklarının yüzde $45^{\prime}$ inde hâkim renktir (Çağan, 2005)."
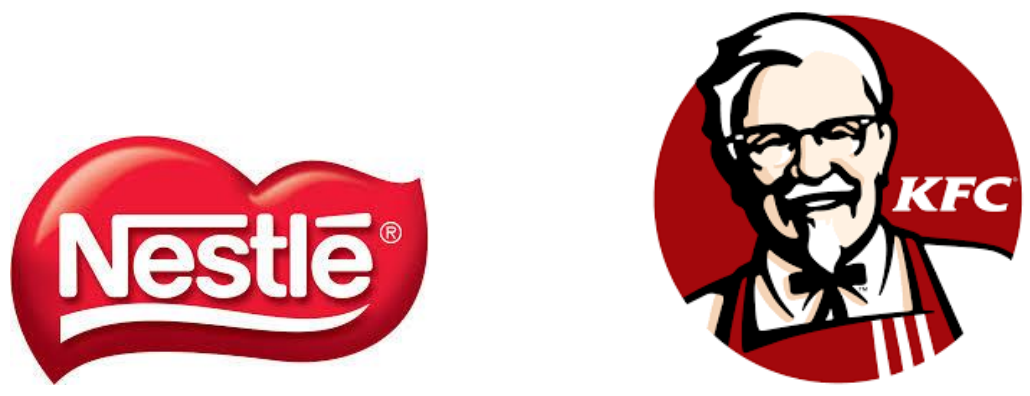

\section{Mavi Renkli Logolar}

Ana soğuk rengimiz olan mavi; gökyüzü, deniz ve suyun rengidir. Mutluluğu ve huzuru temsil eder, dinlendirici bir etkisi vardır. Mavinin görsel etkilerinin yanı sıra bir de psikolojik yönden etkileyen unsurlar vardır. Mavi insanda temizlik, rahatlık ve dinlendirici bir etki yaratır. Dünyaca ünlü markaların logolarına baktığımızda mavi ve tonlarının hakim olduğunu görürüz. Lacivert renk uzay ile bağdaştırılan yönü ile sonsuzluk, büyüklük hissi uyandırır ( Özer, 2014). "Mavi ayrıca düşünme ve karar verme kabiliyetini arttıran bir renktir. Bu özel- liği nedeniyle yaratıcı fikirlerin 
doğmasına neden olmaktadır. Sanatsal duyguların ve ilham kaynaklarının geliştirilmesi geniş ölçüde bu rengin enerjisine bağlı olmaktadır. Bunun yanında, inanma duygusunu ortaya çıaran ve kuvvetlendiren bir renktir" (Parlak, 2006)

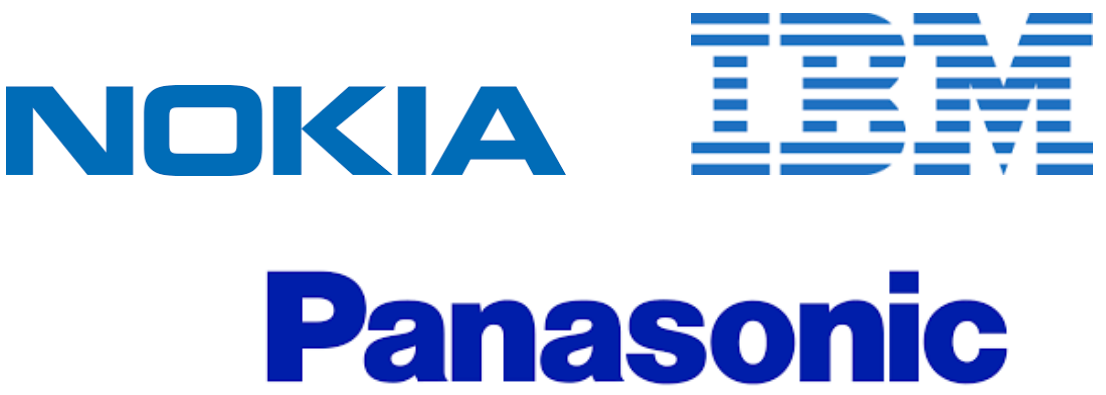

\section{Yeşil Renkli Logolar}

Yeşil doğanın yaşam rengidir. Huzur verici dinlendirici etkiye sahiptir. Yeşil doğallığı, tazeliği ve güveni çağrıştırdığı için gıda sektöründe, doğayla alakalı kurum ve kuruluşlarda ve bankaların logolarında karşımıza çıkabilir. Ayrıca sağlık sektörü de yine yeşil rengi tercih edebilir. "Yeşil, ruhsal anlamda; gerginliği, psikolojik anlamda; sebatkâr ve metin olmayı ifade eder. Resimsel olarak güven ve emniyet, mantık, düșünce, muhakeme, doğa, nemlilik kavramları ile birlikte düşünülür. Toplumsal anlamda sağlam, stabil, sebatkar değerleri ifade eder" (Gümüştekin,1999).
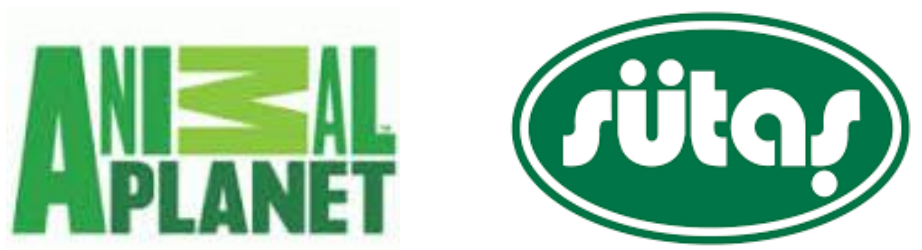


\section{Sarı Renkli Logolar}

$\mathrm{Bu}$ renk yeni firsatların, akıllılığın ve zekanın öğrenilmesini yansıtabilir. "Kanınızdaki damarların daha düzenli işlemesini, sinir sisteminizin düzenli, zihninizin açık ve dikkatinizin artmasını istiyorsanız bu renge uzun süre bakmalısınız" (Çağan, 2005). Sarı renk tek başına kullanıldığında zayıf kalacak bir renk olduğu için genelde destekleyici renk olarak kullanılır.
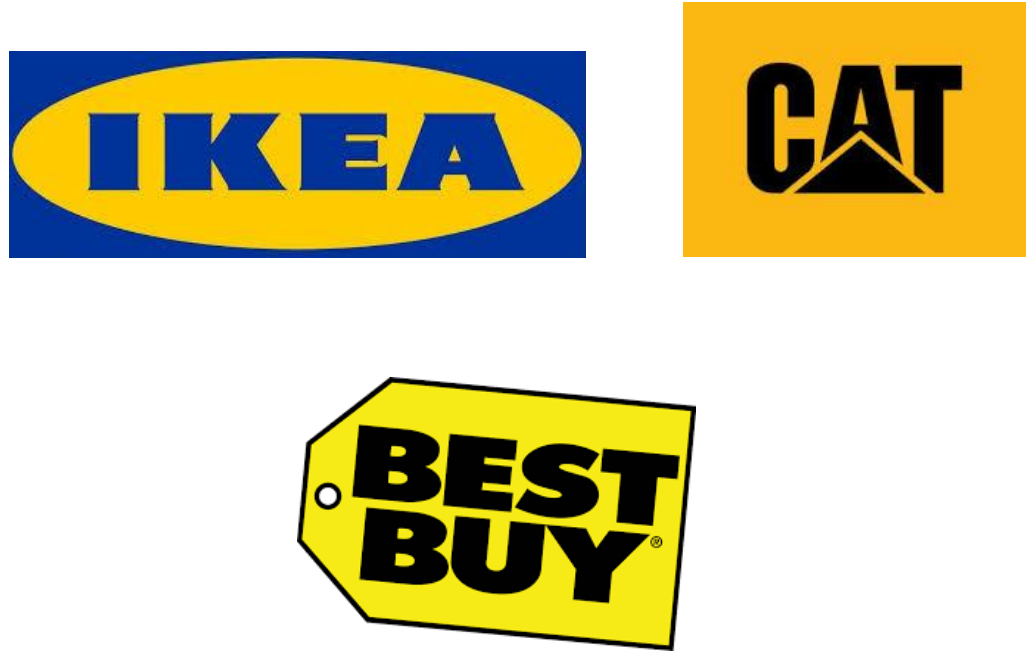

\section{Kahverengi Logolar}

Kahverengi bize toprağı ve ahşabı hatırlatır. Genellikle ciddi, sade ve gösterişten uzak etkisi vardır. Bilinen kahve markalarının logolarında bu rengi görmek mümkündür. İnsanın içini ısıtan doğal bir lezzet olarak bize kahve içme ihtiyacımızı hatırlatmaktadır. Aynı zamanda kahverenginin iştah açıcı özelliği de bilinmektedir. Yemek sektöründe sıkça kullanılmasının sebebi de bu özelliğindendir. 


\section{$\mathbb{N}$ \\ NESPRESSO.}
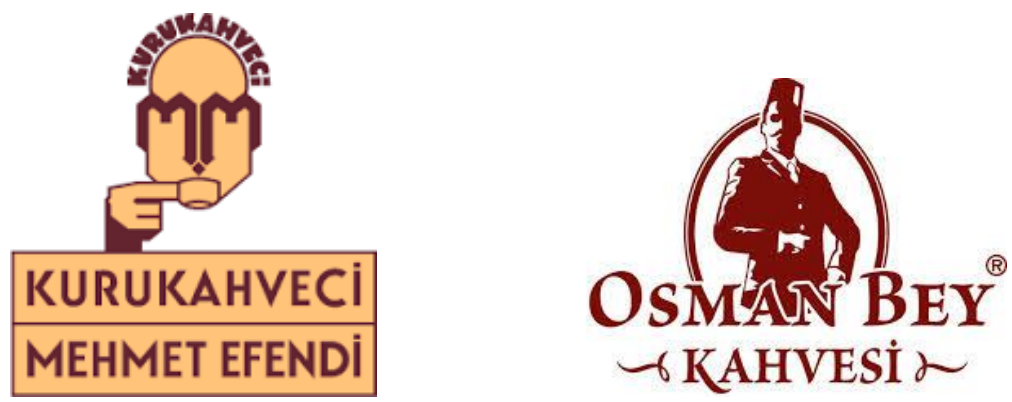

\section{Siyah Renkli Logolar}

Tüm renklerin karışımından elde edilen siyah; gücü, cesareti, otoriteyi, resmiyeti, gizliliği ve sadeliği temsil eder. Batı dünyasında ve bizim kültürümüzde matemin rengidir. Siyah konsantrasyonu arttıran özelliği nedeniyle markaların bir çoğunda tercih edilir. "Siyah; umutsuzluğu, başkaldırıyı, bilinmezliği, ölümü ve matemi simgelemektedir. Bu sebeple matem giysileri birçok kültürde genellikle siyah olmaktadır. Beyaz ise aydınlık, sakinlik, özgürlük, teslimiyet, hoşgörü, bağlanma, temizlik, saflık, tazelik ve masumiyetin rengidir. Gelinliklerin beyaz renkte olması, beyazın bireylerde söz konusu çağrışımları yapmasından kaynaklanmaktadır" (Çallı, 2007).

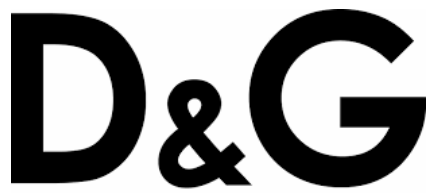

DOLCE \& GABBANA

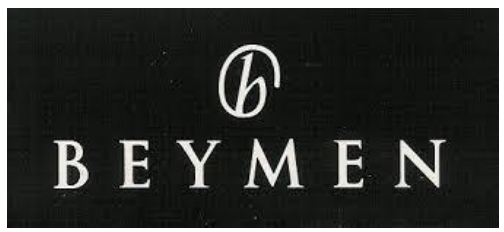




\section{GUCCI \\ Q)}

\section{Sonuç}

İnsanlık tarihimizin oluşumunda bu yana renklerin üzerimizdeki etkisi oldukça fazladır. Yıllar boyunca da renkler kafamızda şekillenmiş, belirli anlamlar ifade etmeye başlamıştır. Renkler belirli kategorilere ayrılmış ve birlikte kullanılacak renklerin de oluşturduğu manalar psikolojik açıdan incelenmiştir.

Logo tasarımında renk olgusu, tasarımın hedef kitleye hitap edebilmesi için ayrıştırıcı unsurlardan bir tanesidir. Grafik tasarımı açısından incelendiğinde rengin tasarıma kattığı ifade, tüketiciyi çekebilmeli, duygusal olarak bağlayabilmelidir. Renklerin toplum tarafindan oluşturduğu his, ürünün tanıtımı için büyük tol oynar. Fakat tasarımcının dikkat etmesi gereken unsur, tasarımın kullanılacağı bölgenin belirlenmesi, kültürel açıdan değerlendirilmesi, kabul edilen değerlerin renk açısından doğru karşılığının bulunabilmesidir. Gerekli saptamalar yapıldıktan sonra logonun oluşumundaki diğer destekleyici unsurlarla birlikte doğru ve çarpıcı renk kullanımı, başarılı bir tasarımın ortaya çıkmasını sağlamaktadır. Özellikle hazırlanan logolarda ya da ambalaj tasarımlarında renk-ürün bağdaşması çok önemlidir. Bu nedenle de tasarımcının renklerin anlamlarını iyi bilmesi ve doğru uygulaması gerekmektedir. Sonuç olarak logo oluşumunda renk algısının büyük bir etkisi olduğu inkar edilemez bir gerçektir. Yaratım sürecinde diğer unsurlarla birlikte renk seçimi de logonun etkisini güçlendirmektedir.

\section{KAYNAKLAR}

AKINCI, M. Markada Kurumsal Kimlik ve İmaj. İstanbul. Işıl Ofset. 1998.

ARIKAN, A. Grafik Tasarımda Görsel Alg1. Konya: Eğitim Akademi Yayınlar1. 2008. 
ATALAYER, F. Temel Sanat Öğeleri. Anadolu Üniversitesi Yayınları. Eskişehir. 1994.

ÇAĞAN, M. Sizin Renkleriniz. İstanbul Birharf Yayınları. 2005.

ÇALLI, D. Bir Sözsüz İletişim Ögesi Olarak Renk ve Renk Kullanımının Basılı Reklam Araçlarında Tüketici Algısı Üzerine Etkisi. 2007.

GÖKAYDIN, N. Eğitimde Tasarım ve Görsel Algı. İstanbul: MEB Basımevi. 1998.

GÜMÜŞTEKIN, N.K. Grafik Sanatlarda İletişim Elemanı Olarak Renk ve Biçimin Farklı Toplumlarda Algılanma ve Etkileşimleri. Sanatta Yeterlilik Tezi. İzmir: Dokuz Eylül Üniversitesi. 1999.

HOLTZSCHUE, L. Rengi Anlamak Tasarımcılar İçin Kılavuz Kitap. F. Akdenizli (çev). İzmir: Duvar Yayınları. 2009.

HURVVITZ, A., DAY, M. Children And Their Art (Methods for the Elementary School) Florida USA: Harcourt Brace College Publishers. 1995.

MITTLER, G. A. Art in Focus. Illinois: Glencoe/McGraw-Hill ine. 1994.

ÖZER, A. Logo Tasarımında Marka Algısı. İstanbul Arel Üniversitesi. 2014.

ÖZTUNA, H. Y. Temel Tasarım Öğeleri "Renk". Grafik Tasarım Görsel İletişim Kültürü Dergisi. 8. 88- 91. 2007.

PARLAK, H. Temel Grafik Tasarım Bilgisi. İzmir: Ege Üniversitesi Basimevi. 2006.

TÜRK, A. Satışı Arttıran Renkler. http://www.xerox.com/news/newsarchieve/2011/tur-color-sales-080911/trtr.html 2011.

WHEELER, A. Designing Brand İdentitiy. New Jersey: John Wiley and Sons. 2003. 